\title{
Social Disadvantage: Cause or Consequence of Impending Psychosis?
}

\author{
Simona A. Stilo*,1,2, Marta Di Forti², Valeria Mondelli³, Aurora M. Falcone², Manuela Russo², Jennifer O'Connor' ${ }^{2}$, \\ Emma Palmer ${ }^{1}$, Alessandra Paparelli², Anna Kolliakou' ${ }^{2}$, Miriam Sirianni ${ }^{2}$, Heather Taylor ${ }^{2}$, Rowena Handley², \\ Paola Dazzan ${ }^{2}$, Carmine Pariante ${ }^{3}$, Tiago R. Marques ${ }^{2}$, Rocco Zoccali ${ }^{4}$, Anthony David ${ }^{2}$, Robin M. Murray ${ }^{2}$, and \\ Craig Morgan ${ }^{1,2}$ \\ ${ }^{1}$ Department of Health Service and Population Research, Institute of Psychiatry, King's College London, London, UK; ${ }^{2}$ Department \\ of Psychosis Studies, Institute of Psychiatry, King's College London, London, UK; ${ }^{3}$ Department of Psychological Medicine, Institute \\ of Psychiatry, King's College London, London, UK; ${ }^{4}$ Department of Neuroscience, University of Messina, Messina, Italy
}

*To whom correspondence should be addressed; Department of Health Service and Population Research, PO 52, Institute of Psychiatry, De Crespigny Park, London SE5 8AF, UK; tel: +44 (0)207 848 5842, fax: +44 (0)2078480287, e-mail: simona.stilo@kcl.ac.uk

Background: An association between social disadvantage and established psychosis is well documented in the literature, but there remains a lack of data on the social circumstances of patients before they became ill. We investigated whether social disadvantage at, and prior to, first contact with psychiatric services, is associated with psychosis. Method: We collected information on social disadvantage in childhood and adulthood from 278 cases presenting with their first episode of psychosis to the South London and Maudsley National Health Service Foundation Trust and from 226 controls recruited from the local population. Three markers of childhood social disadvantage and 3 markers of disadvantage in adulthood were analyzed. Results: Long term separation from, and death of, a parent before the age of 17 years were both strongly associated with a 2- to 3 -fold-increased odds of psychosis. Cases were also significantly more likely to report 2 or more markers of adult social disadvantage than healthy controls $(O R=9.03)$ at the time of the first presentation with psychosis, independent of a number of confounders. When we repeated these analyses for long-standing adult social disadvantage, we found that the strength of the association decreased but still remained significant for 1 year $(O R=5.67)$ and 5 years $(\mathrm{OR}=2.57)$ prior to the first contact. Conclusions: Social disadvantage indexes exposure to factors operating prior to onset that increase the risk of psychosis, both during childhood and adulthood.

Key words: schizophrenia/social disadvantage/unemployment/separation/loss/environment

A rich body of literature has consistently reported an association between loss of a parent in childhood either by death or separation and increased risk of depression in adulthood. ${ }^{1-3}$ Social disadvantage in childhood has also been related to substance abuse, poor physical health in adult life, and poor outcome in schizophrenia. ${ }^{4} \mathrm{~A}$ recent meta-analysis including 36 studies found evidence that childhood adversity is substantially associated with an increased risk for psychosis and suggested that studies should focus on differentiating adversity types. ${ }^{5}$ Special attention has been given to social inequality at birth and the parental socioeconomic situation of people who develop psychosis ${ }^{6-8}$; but there are still unanswered questions. As a marker of social disadvantage in childhood we focused on long-term separation from, or death of, one or both parents; only a few studies have specifically examined these associations. ${ }^{9,10}$ Both studies found that each marker of childhood disadvantage or loss was associated with a 2- to 3-fold-increased odds of psychosis. No studies have looked at family arrangements before the age of 17 yet.

Individuals with established psychotic disorders often experience marked social disadvantage in adult life; they are more likely to live alone, ${ }^{11}$ be unemployed, ${ }^{12}$ and have few close relationships. ${ }^{13}$ However, it is unclear whether these are a consequence of the illness or whether they antedate the illness and if the latter, whether they contribute to its onset. Unfortunately, there is a lack of data on the social circumstances of psychotic patients before they became ill and only a few studies have tried systematically to investigate this. A Danish study of 5341 patients showed that schizophrenia is associated with poor social achievement long before the first admission. ${ }^{14}$ Morgan et al investigated the relationship between psychosis and a number of current and long-term indicators of adult social disadvantage in 390 cases with a first episode of psychosis and 391 healthy controls drawn from the UK-based AESOP study; all current and long-term indicators (eg, 
unemployment, living alone, and social housing) were associated with increased odds of psychosis. ${ }^{15}$

In this article, our focus is on social disadvantage (1) in childhood, (2) at 5 years and 1 year prior to first presentation to psychiatric services, and (3) at first presentation with psychosis and the association of any disadvantage with psychosis.

\section{Method}

This research forms part of the Genetic and Psychosis study (further details can be found in Di Forti et al). ${ }^{16}$ This is a case-control study, conducted between December 2005 and October 2010, of patients with a first episode of psychosis (ICD-10 F20-F29, F30-F33; World Health Organization, 1992) ${ }^{17}$ who presented to psychiatric services within defined catchment areas in south-east London covered by the South London and Maudsley (SlaM) National Health Service Foundation Trust; SLaM provides mental health services to people from the London boroughs of Croydon, Lambeth, and Southwark.

\section{Cases}

The inclusion criteria for cases were age 18-65 years; resident within defined catchment areas in south-east London (Croydon, Lambeth, and Southwark); presentation with a first episode of psychosis within the time-frame of the study; and no previous contact with mental health services for psychosis. We established clinical diagnosis by administering the Operational Criteria checklist for psychotic illness. ${ }^{18}$

Exclusion criteria were evidence of psychotic symptoms precipitated by an organic cause; transient psychotic symptoms resulting from acute intoxication as defined by ICD-10; moderate or severe learning disabilities (as defined by ICD-10, World Health Organization, 1992) ${ }^{17}$; and poor English fluency (ie, required a translator).

Each week, a team of researchers regularly checked all points of potential contact with specialist adult in-patient and out-patients units in SLaM, interviewed staff, and reviewed clinical notes. Because of this recruitment strategy, our sample should be representative of all first-episode psychosis patients presenting to the SLaM services from the defined catchment area over the 5-year period. Each patient meeting inclusion criteria was approached and informed consent to participate was sought.

Of the individuals with a first episode of psychosis approached, 20\% (145) refused to participate and 596 agreed to participate (further details can be found in Di Forti et al, 2012). ${ }^{19}$

Complete data on social disadvantage was available for $278(47 \%)$ of these cases (see below).

\section{Controls}

During the same period, we recruited 226 controls, aged 18-65. Particular attention was directed toward obtaining a control sample representative of the general population from the local boroughs served by SlaM. This was done by means of internet and newspaper advertisements, and distribution of leaflets at train stations, shops, and job centers. Those who agreed to participate were administered the Psychosis Screening Questionnaire ${ }^{20}$ and excluded if they met criteria for a psychotic disorder or reported a previous diagnosis of psychotic illness.

\section{Data Collection}

We collected data on indicators of subjects' current and past social circumstances using the Medical Research Council Sociodemographic Schedule, which covers the following areas: personal background and demographic characteristics including information on ethnicity, age, sex, migration, education, occupation, living, and relationship status; and past and recent significant life events including early parental loss and separation and family arrangements. ${ }^{21}$

Childhood. We focused on separation from, death of, one or both parents, and family arrangements before the age of 17. For the analyses, we defined long-term separation as a separation (not living in same household) from one or both parents for 6 months or more resulting from family breakdown (parental separation or divorce, parent-abandoned subject) before the age of 17 . We asked if either parent died and/or if the subject was separated from either parent for 6 months or more before the age of 17 . Family arrangements refer to mother and father figures that the subject lived with, for at least 1 year before the age of 17 (eg, natural mother/father, step-mother/step-father, etc.). Separations consequent upon planned migrations were not included.

Adulthood. We included a series of indicators in 3 domains: (1) employment; (2) living arrangements; and (3) relationship. We distinguished between those who were employed, those who were unemployed, and those who were economically inactive (ie, students and house persons). ${ }^{22}$

We distinguished between those who lived alone, those who lived with relatives, and those who lived with others. We distinguished between those who were single and those who were in a relationship. Where possible, we distinguished between current and long-term (at 1 year and at 5 years prior to presentation) circumstances.

To assess the impact of cumulative adult disadvantage, we created indices of current and long-term social disadvantage using, where possible, 1 indicator variable from each of the domains noted above (ie, employment, living arrangements, and relationships). We dichotomized these variables to indicate the presence or absence of an indicator, with a score of 1 for present (eg, unemployed) and 0 for absent. This produced a potential range on the current and long-term indices (ie, at 1 year and 5 years pre-first contact) of 0 to 3 . 
Confounders. We collected data on a number of potential confounding factors. Information on cannabis and use of illicit drugs was obtained from all subjects using the Cannabis Experience Questionnaire. ${ }^{16,23}$ Information on age, gender, self-ascribed ethnicity, education, place of birth, social class at birth, and life events was collected as part of the sociodemographic interview. ${ }^{21}$ All participants were asked about family history of mental illness in first-degree relatives using the Family Interview for Genetic Studies. ${ }^{24}$ IQ and premorbid IQ were calculated using the Wechsler Adult Intelligence Scale III $^{25}$ and National Adult Reading Test, respectively. ${ }^{26}$

Other Variables. As in previous studies, duration of untreated psychosis (DUP) was defined as the period in weeks from the onset of psychosis to first contact with statutory mental health services. ${ }^{27,28}$ Ethical approval for the study was obtained from the SLaM and Institute of Psychiatry Research Ethics Committee.

Analysis. Logistic regression was used to analyze the relationship between parental separation and loss in childhood and case-control status. In all multivariable analyses, the following variables were controlled: age, gender, and ethnicity. In addition, we further adjusted for each of the following variables (separately, rather than simultaneously due to missing data and consequent reduction of statistical power): place of birth, social class at birth, life events, psychiatric family history, family history of psychosis, IQ, premorbid IQ, education, cannabis, and substance abuse of other drugs. The same approach was used to analyze the relationship between indicators of social disadvantage in adulthood and case-control status at and prior to the first contact with psychiatric services while controlling for potential confounders. Analyses were conducted using Stata version 10 (Stata, 2008). ${ }^{29}$

\section{Results}

\section{Sample Characteristics}

During the 5-year study period, 596 patients with a first episode of psychosis and 226 controls agreed to participate. However, because of nonresponse to some items, dropout (often because of discharge before the end of the assessment), and migration (subject went back to the country of origin), we were able to gather complete information on current and past social circumstances from 278 patients. Patients not included in the analysis were not significantly different in age, gender, and diagnosis from those included; however, they were significantly more likely to belong to the Black Caribbean ethnic group (OR $1.99,95 \%$ CI $1.19-3.30$ ).

The basic sociodemographic characteristics are summarized in table 1. Differences between cases and controls in gender, ethnicity, and family history of psychosis reflect well-established associations.

\section{Social Disadvantage in Childhood}

$11 \%$ of patients had experienced loss of a parent due to death before the age of 17 and $40 \%$ had experienced separation. Compared with controls, cases were approximately 3 times more likely to have had a parent die before the age of 17 (OR 3.04, 95\% CI 1.43-6.45) and approximately 2 times more likely to have experienced a long-term separation from one or both parents before the age of 17 (OR $1.98,95 \%$ CI 1.32-2.97) (table 2). These findings held, with some attenuation, when the ORs were adjusted for age, gender, and ethnicity. When we further adjusted (in turn and separately) for other potential confounders such as place of birth, social class at birth, life events, psychiatric family history, family history of psychosis, IQ, premorbid IQ, education, cannabis, and substance abuse of other drugs, the findings held with minimal attenuation of odds ratios (data not shown, available on request). There was no evidence that the effect of separation varied by cause of separation (data not shown, available on request).

We also looked at family arrangements during childhood and found that cases were 2.56 times $(95 \%$ CI 1.73-3.77) more likely than controls to have had 2 or more family arrangements before age 17 (table 2).

\section{Social Disadvantage in Adulthood}

Across all the domains considered, cases were more likely to be socially disadvantaged than were controls at first presentation (table 2). These associations held after account was taken of age, gender, and ethnicity, and were evident 1 year prior to first contact with psychosis (albeit to lesser degrees). However, at 5 years prior to first contact, the only variable associated with case status was unemployment.

\section{Cumulative Impact of Adult Social Disadvantage}

From the indicators used in this study, we constructed indices of current and long-term social disadvantage in adult life using the following variables: unemployment, living alone and being single. This allowed us to investigate whether the odds of psychosis increased in line with increasing disadvantage. This is indeed what we found. Table 3 shows that the odds ratios increase in linear fashion as the number of markers present increase.

Sixty-seven percent $(n=189)$ of patients, compared with $19 \%(n=43)$ of controls, reported 2 or more markers of adult social disadvantage. In other words, cases were around 9 times more likely than controls to report 2 or more markers of disadvantage at first presentation with psychosis (OR 9.03, 95\% CI 5.60-14.58). This association remained when adjusted for age, gender, and ethnicity (OR 9.47, 95\% CI 6.09-14.71) (figure 1). We repeated these analyses for social disadvantage at 1 year and 5 years previously; at both points, social disadvantage was highly associated with later caseness. Calculating the 
Table 1. Basic Sociodemographic Characteristics by Case-Control Status

\begin{tabular}{|c|c|c|c|c|c|}
\hline & Controls $(n=226)$ & Cases $(n=278)$ & $t$ & df & $P$ \\
\hline \multicolumn{6}{|l|}{ Age (yr) } \\
\hline Mean & 28 & 28 & 26.21 & 45 & .42 \\
\hline \multirow[t]{2}{*}{ SD } & 9.80 & 9.04 & & & \\
\hline & $\mathrm{n}(\%)$ & $\mathrm{n}(\%)$ & $x^{2}$ & $\mathrm{df}$ & $P$ \\
\hline \multicolumn{6}{|l|}{ Gender } \\
\hline Male & $122(53.98)$ & $177(63.67)$ & 4.84 & 1 & .02 \\
\hline Female & $104(46.02)$ & $101(36.33)$ & & & \\
\hline \multicolumn{6}{|l|}{ Ethnicity } \\
\hline White British & $85(37.61)$ & $72(25.90)$ & 23.87 & 5 & $<.001$ \\
\hline Asian & $13(5.75)$ & $23(8.27)$ & & & \\
\hline Black Caribbean & $34(15.04)$ & $39(14.03)$ & & & \\
\hline Black African & $33(14.60)$ & $72(25.90)$ & & & \\
\hline Others & $30(13.27)$ & $54(19.42)$ & & & \\
\hline Non-British White & $31(13.72)$ & $18(6.47)$ & & & \\
\hline \multicolumn{6}{|l|}{ Education $^{\mathrm{a}}$} \\
\hline No qualification & $6(2.65)$ & $41(14.86)$ & 78.31 & 4 & $<.001$ \\
\hline GCSE/O levels & $23(10.18)$ & $74(26.81)$ & & & \\
\hline A levels & $51(22.57)$ & $37(13.41)$ & & & \\
\hline Vocational/college & $36(15.93)$ & $68(24.64)$ & & & \\
\hline University/professional & $110(48.67)$ & $56(20.29)$ & & & \\
\hline \multicolumn{6}{|l|}{ Place of Birth ${ }^{\mathrm{b}}$} \\
\hline UK Born & $143(64.13)$ & $145(54.10)$ & 5.04 & 1 & .025 \\
\hline Non-UK born & $80(35.87)$ & $123(45.90)$ & & & \\
\hline \multicolumn{6}{|l|}{ Family history of psychosis ${ }^{c}$} \\
\hline Any & $15(7.14)$ & $45(20.83)$ & 16.49 & 1 & $<.001$ \\
\hline None & $195(92.86)$ & $171(79.17)$ & & & \\
\hline
\end{tabular}

Note: df, degrees of freedom.

${ }^{\mathrm{a}}$ Missing values: 2 .

${ }^{\mathrm{b}}$ Missing values: 13 .

'Missing values: 78 .

adjusted OR, cases were 5.67 (CI 3.57-9.02) times more likely than controls to report social disadvantage 1 year previously, and 2.68 (CI 1.62-4.45) times more likely to report social disadvantage 5 years previously, than controls (figure 1).

These results were independent of a number of potential confounders (adjusted in turn and separately): place of birth, social class at birth, IQ, premorbid IQ, and education, life events and separation and loss of a parent before age of 17 , substance abuse such as cannabis and other drugs, as well as a psychiatric family history and psychosis family history (Tables available on request).

This pattern applied to schizophrenia, as well as to other psychotic cases. However, when we compared subjects with affective psychoses [Bipolar type I $(n=40)$ and Schizoaffective $(n=23)$ ] and subjects with nonaffective psychoses [Schizophrenia $(n=46)$, Schizophreniform disorder $(n=52)$, Psychotic disorder NOS (35), Delusional Disorder $(n=6)$ ] social disadvantage was more pronounced for patients with nonaffective psychoses $(P<$ .001 , OR 2.84, 95\% CI 1.49-5.39). Nevertheless, subjects suffering from affective psychoses were significantly more likely to report adult social disadvantage $(P<.001$, OR 4.12, 95\% CI 2.21-7.68) than controls. When we compared those with bipolar disorder $(n=40)$ and those with depressive psychosis $(n=14)$, the difference was not significant $(P=.645)$.

Of the 278 patients included in the analysis, we were able to calculate the DUP for 215 (mean 23.27 weeks, SD 76.07). Of these, 193 had a DUP shorter than 1 year, 10 had a DUP between 1 and 2 years, and only 12 people had a DUP longer than 2 years. Analyses were repeated for those with a DUP of less than 1 year and the association between adult social disadvantage and psychosis remained the same $(P<.001$, OR $8.87,95 \%$ CI 5.46-14.40).

\section{Restricted Samples and Adult Social Disadvantage}

In order to investigate whether the young age of some of our participants affected our findings, we excluded people younger than 21 , assuming that young people are more likely to live with their parents and to be in education, and repeated all the analyses. The associations between adult social disadvantage and psychosis remained. Cases were around 8 times more likely than controls to report 2 or more markers of disadvantage (aOR 8.53, 95\% CI 5.20-13.99) at first contact with psychiatric services, 5 times more likely 
Table 2. Indicators of Social Disadvantage in Childhood and Adulthood by Case-Control Status

\begin{tabular}{|c|c|c|c|c|}
\hline & Controls $(n=226) n(\%)$ & Cases $(n=278) n(\%)$ & Unadjusted OR $(95 \% \mathrm{CI})$ & Adjusted aOR $(95 \% \mathrm{CI})$ \\
\hline \multicolumn{5}{|l|}{ Childhood } \\
\hline \multicolumn{5}{|l|}{ Separation, death ${ }^{\mathrm{a}}$} \\
\hline None & $146(66.67)$ & $122(48.22)$ & 1.00 & 1.00 \\
\hline Parental death & $11(5.02)$ & $28(11.07)$ & $3.04(1.43-6.45)$ & $2.74(1.27-5.88)$ \\
\hline Separation & $62(28.31)$ & $103(40.71)$ & $1.98(1.32-2.97)$ & $1.84(1.21-2.80)$ \\
\hline \multicolumn{5}{|l|}{$\begin{array}{l}\text { Number of Family } \\
\text { arrangements }^{\mathrm{b}}\end{array}$} \\
\hline 1 & $152(68.78)$ & $117(46.25)$ & 1.00 & 1.00 \\
\hline$\geq 2$ & $69(31.22)$ & $136(53.75)$ & $2.56(1.73-3.77)$ & $2.44(1.63-3.65)$ \\
\hline \multicolumn{5}{|l|}{5 years prior to contact } \\
\hline \multicolumn{5}{|l|}{ Living arrangements ${ }^{\mathrm{c}}$} \\
\hline Live with Others & $74(32.74)$ & $79(28.73)$ & 1.00 & 1.00 \\
\hline Live Alone & $38(16.81)$ & $53(19.27)$ & $1.30(0.77-2.21)$ & $1.19(0.69-2.07)$ \\
\hline Live with relatives & $114(50.44)$ & $143(52.00)$ & $1.17(0.78-1.75)$ & $1.06(0.64-1.73)$ \\
\hline \multicolumn{5}{|l|}{ Relationship status $^{\mathrm{d}}$} \\
\hline In a stable Relationship & $96(42.48)$ & $112(41.33)$ & 1.00 & 1.00 \\
\hline Single & $130(57.52)$ & $159(58.67)$ & $1.04(0.73-1.49)$ & $1.02(0.69-1.51)$ \\
\hline \multicolumn{5}{|l|}{ Employment ${ }^{\mathrm{e}}$} \\
\hline Employed & $110(48.67)$ & $133(48.54)$ & 1.00 & 1.00 \\
\hline Unemployed & $17(7.52)$ & $68(24.82)$ & $3.30(1.80-6.05)$ & $3.40(1.84-6.26)$ \\
\hline Economically inactive & $99(43.81)$ & $73(26.64)$ & $0.60(0.40-0.90)$ & $0.49(0.31-0.79)$ \\
\hline \multicolumn{5}{|l|}{1 year prior to contact } \\
\hline \multicolumn{5}{|l|}{ Living arrangements ${ }^{\mathrm{f}}$} \\
\hline Live with others & $117(51.77)$ & $84(30.43)$ & 1.00 & 1.00 \\
\hline Live alone & $40(17.70)$ & $96(34.78)$ & $3.34(2.06-5.42)$ & $3.04(1.88-4.91)$ \\
\hline Live with relatives & $69(30.53)$ & $96(34.78)$ & $1.93(1.26-2.96)$ & $1.79(1.13-2.85)$ \\
\hline \multicolumn{5}{|l|}{ Relationship status $^{\mathrm{c}}$} \\
\hline In a stable relationship & $116(51.33)$ & $102(37.09)$ & 1.00 & 1.00 \\
\hline Single & $110(48.67)$ & $173(62.91)$ & $1.78(1.24-2.56)$ & $1.65(1.14-2.40)$ \\
\hline \multicolumn{5}{|l|}{ Employment $^{\mathrm{d}}$} \\
\hline Employed & $135(59.73)$ & $126(45.65)$ & 1.00 & 1.00 \\
\hline Unemployed & $30(13.27)$ & $126(45.65)$ & $4.50(2.74-7.36)$ & $4.71(2.89-7.67)$ \\
\hline Economically inactive & $61(26.99)$ & $24(8.70)$ & $0.42(0.24-0.72)$ & $0.33(0.18-0.59)$ \\
\hline \multicolumn{5}{|l|}{ At contact } \\
\hline \multicolumn{5}{|l|}{ Living arrangements } \\
\hline Live with others & $127(56.19)$ & $66(23.74)$ & 1.00 & 1.00 \\
\hline Live alone & $42(18.58)$ & $107(38.49)$ & $4.90(2.96-8.09)$ & $4.55(2.80-7.38)$ \\
\hline Live with relatives & $57(25.22)$ & $105(37.77)$ & $3.54(2.23-5.62)$ & $3.19(1.99-5.13)$ \\
\hline \multicolumn{5}{|l|}{ Relationship status } \\
\hline In a stable Relationship & $104(46.02)$ & $61(21.94)$ & 1.00 & 1.00 \\
\hline Single & $122(53.98)$ & $217(78.06)$ & $3.03(2.03-4.52)$ & $2.86(1.91-4.29)$ \\
\hline \multicolumn{5}{|l|}{ Employment } \\
\hline Employed & $128(56.64)$ & $68(24.46)$ & 1.00 & 1.00 \\
\hline Unemployed & $42(18.58)$ & $188(67.63)$ & $8.42(5.06-14.00)$ & $8.24(5.19-13.07)$ \\
\hline Economically inactive & $56(24.78)$ & $22(7.91)$ & $0.73(0.41-1.31)$ & $0.60(0.32-1.12)$ \\
\hline
\end{tabular}

Note: aOR, Adjusted odds ratio (adjusted for age, gender and ethnicity).

Missing values: ${ }^{\mathrm{a}} 32$ missing; ${ }^{\mathrm{b}} 30$ missing; ${ }^{\mathrm{c}} 3$ missing; ${ }^{\mathrm{d}} 7$ missing; ${ }^{\mathrm{e}} 4 \mathrm{missing}$; 2 missing.

than controls to report social disadvantage 1 year previously (aOR 5.32, 95\% CI 3.19-8.88), and around 2 times (aOR 2.43; 95\% CI 1.38-4.28) more likely to report social disadvantage 5 years previously than controls.

In the same way, we repeated all the analyses excluding all the people 21 years or older. There was a clear relationship between case status and social disadvantage in this restricted sample (tables available on request). Again, at each level, cases were progressively more likely to be disadvantaged.

\section{Childhood and Adulthood Disadvantage: Is the Latter a Consequence of the Former?}

It is possible that adult social advantage may be the consequence of childhood social disadvantage. To answer to this question, we analyzed the association between childhood and adulthood social disadvantage. Those patients who experienced social disadvantage in childhood in the form of separation and loss were more likely to report social disadvantage in adulthood (OR 1.73, 95\% CI 1.00$2.99, P=.04)$. 
Table 3. Index of Social Disadvantage in Adulthood (Current and Long-Term)

\begin{tabular}{|c|c|c|c|c|}
\hline & $\begin{array}{l}\text { Controls }(n=226) \\
n(\%)\end{array}$ & $\begin{array}{l}\text { Cases }(n=278) \\
n(\%)\end{array}$ & $\begin{array}{l}\text { Unadjusted OR } \\
(95 \% \mathrm{CI})\end{array}$ & $\begin{array}{l}\text { Adjusted aOR } \\
(95 \% \mathrm{CI})\end{array}$ \\
\hline \multicolumn{5}{|l|}{ Social Disadvantage Index (current) } \\
\hline 0 & $70(30.97)$ & $21(7.55)$ & 1 & 1 \\
\hline 1 & $113(50.00)$ & $68(24.46)$ & $2.00(1.12-3.58)$ & $1.86(1.03-3.36)$ \\
\hline 2 & $36(15.93)$ & $123(44.24)$ & $11.38(5.52-23.47)$ & $11.32(5.98-21.42)$ \\
\hline 3 & $7(3.10)$ & $66(23.74)$ & $31.42(9.07-108.89)$ & $32.55(12.60-84.10)$ \\
\hline \multicolumn{5}{|l|}{ Social Disadvantage Index (1 year previously $)^{\mathrm{a}}$} \\
\hline 0 & $83(36.73)$ & $53(19.34)$ & 1 & 1 \\
\hline 1 & $112(49.56)$ & $91(33.21)$ & $1.27(0.81-1.98)$ & $1.11(0.70-1.76)$ \\
\hline 2 & $25(11.06)$ & $89(32.48)$ & $5.57(3.02-10.28)$ & $5.16(2.90-9.19)$ \\
\hline 3 & $6(2.65)$ & $41(14.96)$ & $10.70(3.85-29.71)$ & $9.85(3.83-25.35)$ \\
\hline \multicolumn{5}{|l|}{ Social Disadvantage Index (5 years previously $)^{\mathrm{b}}$} \\
\hline 0 & $69(30.53)$ & $70(26.02)$ & 1 & 1 \\
\hline 1 & $130(57.52)$ & $129(47.96)$ & $0.97(0.64-1.47)$ & $0.88(0.56-1.37)$ \\
\hline 2 & $26(11.50)$ & $61(22.68)$ & $2.31(1.29-4.12)$ & $2.27(1.26-4.06)$ \\
\hline 3 & $1(0.44)$ & $9(3.35)$ & $8.87(1.04-75.58)$ & $9.60(1.14-80.54)$ \\
\hline
\end{tabular}

Note: Missing values (full sample): ${ }^{\mathrm{a}} 4$ missing; ${ }^{\mathrm{b}} 9$ missing.

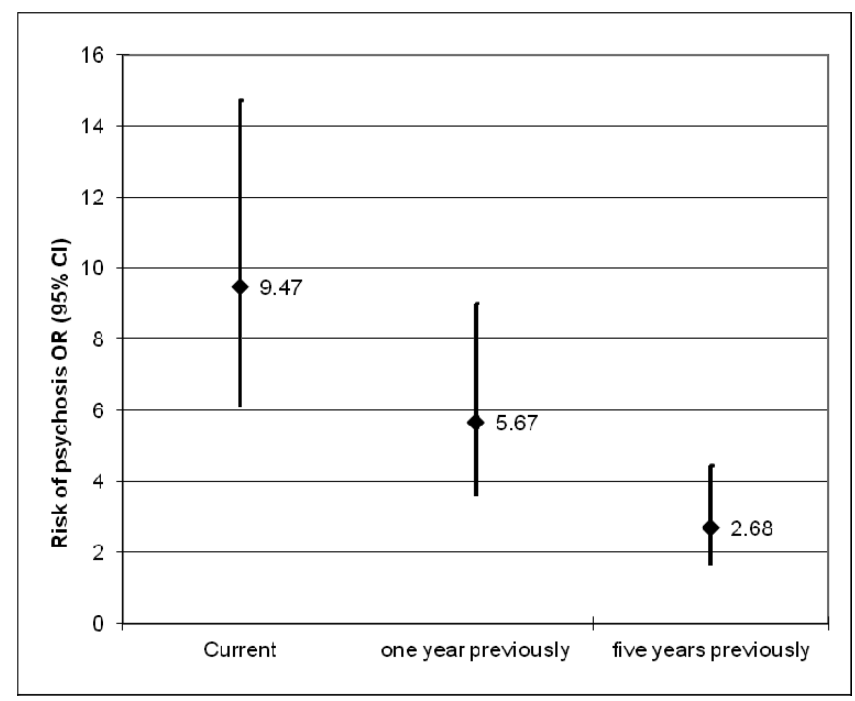

Fig. 1. Social disadvantage (current and 1 and 5 years pre-first contact) and risk of psychosis.

The same pattern did not apply to the control sample (OR 1.29, 95\% CI 0.64-2.61, $P=.46$ ). We calculated the Population Attributable Fraction for cases and found that $19 \%$ of the social disadvantage in adulthood was explained by childhood social disadvantage.

\section{Discussion}

Some clear conclusions emerge from these analyses. The relationship between first-episode psychosis and social disadvantage is very robust. Early and later social disadvantage are both strongly associated with psychosis. Consistent with published studies, ${ }^{9,10}$ long-term separation from and death of a parent before the age of 17 were both strongly associated with approximately 2- to 3 -fold-increased odds of psychosis independent of a number of potential confounders. Even though both were highly significant, the effect of loss due to parental death was more striking than that of separation, and the effect of separation did not vary by cause of separation. One previous study ${ }^{30}$ did not find an association between early separation and loss and psychosis; however, this may be attributable to the low statistical power of that study and the use of a low threshold for separation (1 month). When number of family arrangements was analyzed, our cases were more likely to report 2 or more arrangements, indicating that this variable may also be considered an early marker indexing exposure to risk factors for psychosis.

In our sample, social disadvantage in adult life was also strongly associated with psychosis. All 3 indicators of social disadvantage in adulthood (living alone, being single, and unemployment) were more prevalent in cases than controls at the time of presentation to psychiatric services. The association was still significant 1 year earlier, but the only variable still significant 5 years earlier was employment status. In line with the study by Mallet et al, ${ }^{21}$ unemployment was the strongest factor associated with case status. Furthermore, the percent unemployed in our control sample $(18.5 \%)$ was higher than recently found in a general population survey conducted in the same geographical area $(9.4 \%) .{ }^{31}$ The effect of overestimating levels of unemployment, however, is to underestimate the size of the difference between our cases and our controls. Therefore, our estimate of the extent of the relationship between unemployment and psychosis is likely conservative. However, we cannot implicate unemployment per se because it may be a marker of, eg, financial deprivation, lack of self-esteem, or reduced social networks. 
When we looked at the cumulative impact of social disadvantage, we found a clear linear relationship for both current and long-term indices; ie, the odds of being a case increased in line with increasing number of indicators present. In this, our results replicate the findings from the AESOP study ${ }^{15}$ and extend them by looking back 5 years before the first admission. We were also able to control for a wider range of potential confounders. Controlling for clinical and social variables did not vitiate the strong statistical significance of the findings. Furthermore, social disadvantage was not simply a consequence of the patients having a long DUP, suggesting that disadvantage is already well established before onset of first symptoms, which is in keeping with other studies. ${ }^{32}$ The association also remained when the sample was restricted to people older or younger than 21 , indicating that the age of our participants did not affect our findings.

Two important questions remain. First, is adulthood social disadvantage in first-episode psychosis patients a consequence of childhood disadvantage? This is plausible in part at least because our results show an association between early disadvantage and adult social disadvantage (OR 1.73, 95\% CI 1.00-2.99, $P=.04$ ).

Second, is social disadvantage simply a consequence of functional impairment or decline before onset of psychosis, or is it causal? We cannot fully answer this question due to the cross-sectional and retrospective nature of our findings. However, the results on childhood and adult disadvantage and DUP argue against social disadvantage being simply an epiphenomena of impending illness.

Our findings permit the tentative suggestion that stable relationships, living with someone, and employment may have a protective role in psychosis.

\section{Limitations}

Our results should be interpreted in the context of a number of limitations. One of the main issues is that the case-control design used is not sufficient to take into account all the possible causal pathways that link social disadvantage and psychosis. Although the results of our study show a very strong relationship between social disadvantage and psychosis, we cannot assume a causal role. A cohort study would be more appropriate to elucidate causal links but obviously much more difficult and expensive to carry out, as it would need very large cohorts to generate sufficient numbers with a rare disorder such as schizophrenia; a definitive answer would require one to take into account genetic predisposition.

A second limitation may be the control sample selection. Our method of control recruitment was nonrandom (internet and local newspapers ads, distribution of leaflets at local shops, job centers, and community centers), and this introduces the potential for bias. We were, however, able to compare the characteristics of our control group with those of a large random sample drawn from the same catchment areas for a community survey. In terms of age, gender, and ethnicity, there was no evidence that our control sample was not representative. ${ }^{31}$ Therefore, our recruitment strategy does not ensure (but at the same time does not exclude) the representativeness of the sample.

Third, many other factors, known to be associated with psychosis, may have the potential to confound the relationships with social disadvantage. This urges caution in interpreting these data.

Another important consideration is the distinction between direct and indirect indicators of social disadvantage. Is unemployment to be considered a risk indicator for social disadvantage or a direct measure? ${ }^{33}$ In the same way, are parental separation and death and number of family arrangements merely indicators of parental discord prior to separation and loss and financial and/or other hardships following separation and loss? Whatever the answer, this does not nullify the association.

Then, it is possible that it is not social disadvantage per se that leads to psychosis but inherited genetic susceptibility that predisposes to both social disadvantage and psychosis; our data on family history of psychosis and on family history of psychiatric disorders do not support this but a conclusive result will have to await detailed knowledge of the genetics of psychosis.

Finally, recall bias may have occurred in the reports of our primary exposures. However, there is no evidence that psychosis itself impairs the accuracy of information provided about social disadvantage and the interview was focused on concrete events that people are unlikely to forget.

Associations need not imply causation; however these data add to an increasing body of research that suggests social disadvantage may contribute to precipitating the onset of psychosis or may index exposure to factors that render the individual more vulnerable. Future research will need to further examine these associations and the role of social disadvantage in different ethnic groups as contributory explanation for the higher rates of psychosis among migrants and minority populations. Social disadvantage may be one environmental factor that interacts with genetic predisposition and other environmental factors to cause psychosis.

\section{Funding}

Medical Research Council (G0500817 to Dr Morgan, Dr Murray, and Dr Paola Dazzan); Wellcome Trust (WT087417 to Dr Morgan, Dr Murray, and Dr Paola Dazzan); European Union (European Community's Seventh Framework Program[HEALTH-F2-2009-241909 to Dr Morgan and Dr Murray] [Project EU-GEI]); the 
Department of Health via the National Institute for Health Research (NIHR) Specialist Biomedical Research Centre for Mental Health award to South London; Maudsley NHS Foundation Trust (SLaM); the Institute of Psychiatry at King's College London; Robin Murray: honoraria received from Janssen, Astra-Zeneca, Lilly, BMS, and Roche; Tiago R. Marques: honoraria received from United BioSource.

\section{Acknowledgments}

We thank the Genetic and Psychosis (GAP) study team and the PUMP study team.

\section{References}

1. Brown GW, Harris T, Copeland JR. Depression and loss. $\mathrm{Br}$ J Psychiatry. 1977;130:1-18.

2. Bifulco AT, Brown GW, Harris TO. Childhood loss of parent, lack of adequate parental care and adult depression: a replication. J Affect Disord. 1987;12:115-128.

3. Harris T, Brown GW, Bifulco A. Loss of parent in childhood and adult psychiatric disorder: the role of lack of adequate parental care. Psychol Med. 1986;16:641-659.

4. Rosenberg SD, Lu W, Mueser KT, Jankowski MK, Cournos F. Correlates of adverse childhood events among adults with schizophrenia spectrum disorders. Psychiatr Serv. 2007;58:245-253.

5. Varese F, Smeets F, Drukker M, et al. Childhood Adversities Increase the Risk of Psychosis: a Meta-analysis of Patient-Control, Prospective- and Cross-sectional Cohort Studies. Schizophr Bull. 2012;38:661-671.

6. Harrison G, Gunnell D, Glazebrook C, Page K, Kwiecinski R. Association between schizophrenia and social inequality at birth: case-control study. Br J Psychiatry. 2001;179:346-350.

7. Wicks S, Hjern A, Gunnell D, Lewis G, Dalman C. Social adversity in childhood and the risk of developing psychosis: a national cohort study. Am J Psychiatry. 2005;162: 1652-1657.

8. Werner S, Malaspina D, Rabinowitz J. Socioeconomic status at birth is associated with risk of schizophrenia: population-based multilevel study. Schizophr Bull. 2007;33:1373-1378.

9. Agid O, Shapira B, Zislin J, et al. Environment and vulnerability to major psychiatric illness: a case control study of early parental loss in major depression, bipolar disorder and schizophrenia. Mol Psychiatry. 1999;4:163-172.

10. Morgan C, Kirkbride J, Leff J, et al. Parental separation, loss and psychosis in different ethnic groups: a case-control study. Psychol Med. 2007;37:495-503.

11. Harvey CA, Pantelis C, Taylor J, et al. The Camden schizophrenia surveys. II. High prevalence of schizophrenia in an inner London borough and its relationship to socio-demographic factors. Br J Psychiatry. 1996;168:418-426.

12. Thornicroft G, Strathdee G, Phelan M, et al. Rationale and design. PRiSM Psychosis Study I. Br J Psychiatry. 1998;173:363-370.

13. Walsh E, Leese M, Taylor P, et al. Psychosis in high-security and general psychiatric services: report from the UK700 and special hospitals' treatment resistant schizophrenia groups. Br J Psychiatry. 2002;180:351-357.
14. Agerbo E, Byrne M, Eaton WW, Mortensen PB. Marital and labor market status in the long run in schizophrenia. Arch Gen Psychiatry. 2004;61:28-33.

15. Morgan C, Kirkbride J, Hutchinson G, et al. Cumulative social disadvantage, ethnicity and first-episode psychosis: a case-control study. Psychol Med. 2008;38:1701-1715.

16. Di Forti M, Morgan C, Dazzan P, et al. High-potency cannabis and the risk of psychosis. Br J Psychiatry. 2009;195: 488-491.

17. World Health Organization. International Classification of Diseases, 10th Edition (ICD-10): Classification of Mental and Behavioural Disorders. Geneva, Switzerland: World Health Organization; 1992.

18. McGuffin P, Farmer A, Harvey I. A polydiagnostic application of operational criteria in studies of psychotic illness. Development and reliability of the OPCRIT system. Arch Gen Psychiatry. 1991;48:764-770.

19. Di Forti M, Iyegbe C, Sallis H, et al. Confirmation that the AKT1 (rs2494732) genotype influences the risk of psychosis in cannabis users [published online ahead of print July 26, 2012]. Biol Psychiatry. doi:10.1016/j.biopsych.2012.06.020

20. Bebbington PE, Nayani T. The Psychosis Screening Questionnaire. Int J Methods Psychiatr Res. 1995;5:11-19.

21. Mallett R, Leff J, Bhugra D, Pang D, Zhao JH. Social environment, ethnicity and schizophrenia. A case-control study. Soc Psychiatry Psychiatr Epidemiol. 2002;37:329-335.

22. Bivand P. Who are the 'economically inactive'? Labour Market Analysis, Working Brief. 2005;160:16-18.

23. Barkus EJ, Stirling J, Hopkins RS, Lewis S. Cannabis-induced psychosis-like experiences are associated with high schizotypy. Psychopathology. 2006;39:175-178.

24. Maxwell M. Family interview for genetic studies. Clinical Neurogenetic Branch, Intramural Research Program, NIMH. 1992.

25. Wechsler D. Wechsler Adult Intelligence Scale-Third Edition (WAIS-III) administration and scoring manual. San Antonio, TX: The Psychological Corporation, 1997.

26. Nelson HE, Willison J. National Adult Reading Test manual. 2nd ed. Windsor: NFER-Nelson; 1991.

27. Singh SP, Cooper JE, Fisher HL, et al. Determining the chronology and components of psychosis onset: The Nottingham Onset Schedule (NOS). Schizophr Res. 2005;80:117-130.

28. Morgan C, Abdul-Al R, Lappin JM, et al. Clinical and social determinants of duration of untreated psychosis in the AESOP first-episode psychosis study. Br J Psychiatry. 2006;189:446-452.

29. Stata. STATA Statistical Software, Release 10. College Station, TX: Stata Corporation; 2008.

30. Furukawa T, Mizukawa R, Hirai T, Fujihara S, Kitamura T, Takahashi K. Childhood parental loss and schizophrenia: evidence against pathogenic but for some pathoplastic effects. Psychiatry Res. 1998;81:353-362.

31. Hatch SL, Frissa S, Verdecchia M, et al. Identifying socio-demographic and socioeconomic determinants of health inequalities in a diverse London community: the South East London Community Health (SELCoH) study. BMC Public Health. 2011;11:861.

32. Häfner H, Löffler W, Maurer K, Hambrecht M, an der Heiden W. Depression, negative symptoms, social stagnation and social decline in the early course of schizophrenia. Acta Psychiatr Scand. 1999;100:105-118.

33. Morgan C, Burns T, Fitzpatrick R, Pinfold V, Priebe S. Social exclusion and mental health: conceptual and methodological review. Br J Psychiatry. 2007;191:477-483. 